UDK 639.1.057(497.6)

\title{
DEMOGRAFSKA STRUKTURA ČLANOVA LOVAČKIH ORGANIZACIJA U SREDNJOBOSANSKOM KANTONU ${ }^{1}$ Hunter demography in Central Bosnia Canton
}

\author{
Saša Kunovac ${ }^{1}$, Izet Hadžić ${ }^{2}$, Alen Salkić ${ }^{3}$, Slobodan Ličanin ${ }^{4}$, Ramiz Ćutuk $^{5}$, \\ Mujo Džambo ${ }^{1}$, Dalibor Ballian ${ }^{1}$ i Julijan Glavočević ${ }^{6}$ \\ Šumarski fakultet Sarajevo ${ }^{1}$ \\ LD "Semešnica", Donji Vakuf ${ }^{2}$ \\ LD «Kruščica», Vitez ${ }^{3}$ \\ LD "Vlašić" Travnik ${ }^{4}$ \\ Veterinarski fakultet Sarajevo ${ }^{5}$ \\ LD "Zec" Busovača ${ }^{6}$
}

\begin{abstract}
This paper presents the methodology as well as the main results of a survey carried out by Faculty of Forestry, University of Sarajevo, during 2003 and 2004, amongst Hunting organisations in Central Bosnia Canton. Aim of paper is to present evolution of number of hunters before and after War and their socio-economic structure, education and motives for being hunters in nowadays conditions.
\end{abstract}

Key Words: Hunter population, trend, structure, socio-economic aspect, motivation

\section{Uvod}

Epohe razvoja ljudske civilizacije karakterišu se periodima u kojima su lov i bavljenje lovom bili dominantna zanimanja. U prošlim vremenima stanovništvo je bilo malobrojno, a životinjski svijet jako bogat i raznovrstan. Tada se nije moglo ni zamisliti da će se broj životinjskih vrsta usljed antropogenog djelovanja toliko smanjiti, odnosno da će neke vrste nestati a druge biti dovedene pred nestanak, tako da će biti potrebno angažovanje čovjeka kako bi se ove vrste održale i omogućio njihov razvoj i opstanak. Tokom razvoja čovječanstva, značaj lova se mijenjao od proste fiziološke potrebe za hranom (preživljavanjem) do današnje situacije, kada je lov prvenstveno sport, rekreacija $\mathrm{i}$ hobi, ali i privredna grana. Danas, rekreacija

\footnotetext{
${ }^{1}$ Rad prezentiran na II simpoziju poljoprivrede, veterinarstva, šumarstva i biotehnologije sa međunarodnim učešćem Strategija razvoja domaće proizvodnje, 28 - 30 septembar/rujan 2004 Bihać
} 
savremenog čovjeka je neminovnost: sve brži tempo i način života iziskuje sve veće potrebe za kvalitetnim odmorom. Kao jedan od najkorisnijih i najkvalitetnijih vidova odmora označava se lov, jer omogućava boravak u prirodi, relaksaciju i aktivan odmor, što i jeste najkorisniji oblik rekreacije.

Bosna i Herecegovina, kao zemlja koja je još uvijek daleko od Evropske Unije, posjeduje još uvijek očuvane prirodne potencijale za razvoj i bavljenje lovstvom. Ovi potencijali nikako nisu neiscrpni, i ukoliko se degradacija staništa nastavi sadašnjim tempom, ubrzo ćemo izgubiti ovu prednost, koju još uvijek imamo nad većinom Evropskih zemalja.

Ko i zašto se bavi lovom u Bosni i Hercegovini? Kakvi su ljudi lovci i kakva su njihova razmišljanja? Šta bi promijenili, odnosno kako unaprijediti lovstvo na području u kome žive i bave se lovom?

Da bi saznali odgovor na ova i mnoga druga pitanja, Šumarski fakultet Univerziteta u Sarajevu, u saradnji sa Lovačkim organizacijama, pokrenuo je istraživanje o demografskoj strukturi članova Lovačkih organizacija u Srednjobosanskom kantonu/županiji.

\section{Područje istraživanja}

Srednjobosanski kanton/županija, predstavlja šestu od deset administrativnih jedinica Federacije Bosne i Hercegovine, obuhvata područje Centralne Bosne, sa ukupno 12 opština. Ukupna površina ovog kantona je $3189,00 \mathrm{~km}^{2}$, a ukupan broj stanovnika na području kantona je 245.504 (Federalni zavod za Statistiku-podaci od 31.12.2003.). Gustina naseljenosti je 76,98 stanovnika po $\mathrm{km}^{2}$. Do 1992. godine, u 11 opština na području kantona živjelo je 335.752 stanovnika, a gustina naseljenosti iznosila je 105,28 stanovnika po $\mathrm{km}^{2}$. 


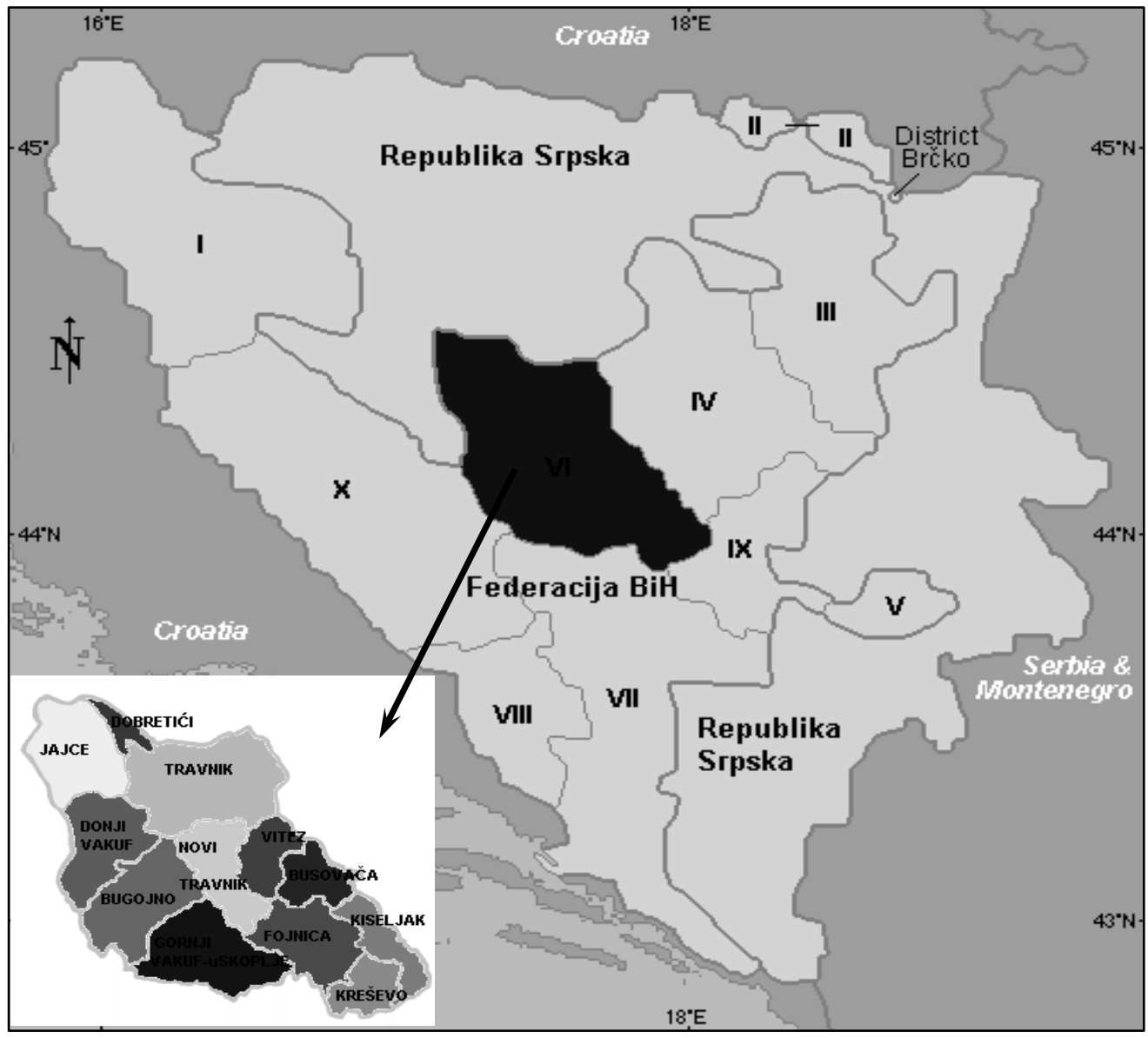

Slika 1. Područje istraživanja

Picture 1. Research area

\section{Materijal i metode}

Za ustanovljavanje demografske strukture članova lovačkih organizacija i udruga na području Srednjobosanskog kantona/županije, koristili smo se anonimnim anketnim upitnikom, kako bi smo dobili što objektivnije podatke. Podaci o broju članova u lovačkim organizacijama do 1992. godine i o broju članova danas, dobijeni su od lovačkih organizacija koje djeluju na prostoru Srednjobosanskog kantona. Podaci o broju stanovnika u području, dobijeni su od Federalnog zavoda za Statistiku. Upitnikom su dobijani podaci o:

- Stručnoj sprema ispitanika

- Zanimanju 
- Starosnoj dobi

- Visini mjesečnih primanja (u KM netto)

- Razlozima bavljenja lovom

- Redovnosti odlazaka u lov

- Da li se namjeravaju baviti lovom i ubuduće

- Visini odstrijelnih taksi (visoke ili ne)

- Značaju lovstva na matičnom području

- Stažu u lovačkoj organizaciji

- Prijedlozima za promjene ili unapređenje lovstva na matičnom području

- Prevoznom sredstvu koje se koristi prilikom odlaska u lov

\begin{tabular}{|c|c|c|c|c|c|c|c|c|c|c|c|c|}
\hline \multirow{2}{*}{\multicolumn{2}{|c|}{\begin{tabular}{|c|} 
Lovačka organiź \\
$\begin{array}{c}\text { Strućna sprema } \\
\text { ispitanika }\end{array}$ \\
\end{tabular}}} & acija: & & & & & & & & & -- & \\
\hline & & \multicolumn{3}{|c|}{\begin{tabular}{c|}
$\begin{array}{c}\text { Visoka stručna } \\
\text { sprema }\end{array}$ \\
\end{tabular}} & \multicolumn{3}{|c|}{ Viša stručna sprema } & \multicolumn{3}{|c|}{$\begin{array}{l}\text { Srednja stručna } \\
\text { sprema }\end{array}$} & \multicolumn{2}{|c|}{ Ostalo } \\
\hline Zanimanie & Ekonomist & \multicolumn{2}{|c|}{ Pravrak } & $\begin{array}{c}\text { Privatri } \\
\text { sektor }\end{array}$ & \multicolumn{2}{|c|}{ Zdravstro } & Student & \multicolumn{2}{|c|}{ Prosvjeta } & $\begin{array}{l}\text { Tehrička } \\
\text { zanimarja }\end{array}$ & Penzione & Ostal \\
\hline \multicolumn{2}{|c|}{ Pol } & \multicolumn{5}{|c|}{ Ženski } & \multicolumn{6}{|c|}{ Muški } \\
\hline \multicolumn{2}{|c|}{ Starosna dob } & \multicolumn{3}{|c|}{ Mladi od 20} & \multicolumn{2}{|l|}{$20-35$} & \multicolumn{3}{|c|}{$36-50$} & $51-65$ & \multicolumn{2}{|c|}{ Stariii od 65} \\
\hline \multicolumn{2}{|c|}{ Mjesto prebivališta } & & & & & \multicolumn{4}{|c|}{ Ostala mjesta u BiH } & \multicolumn{3}{|c|}{ Stranci } \\
\hline \multicolumn{2}{|c|}{$\begin{array}{l}\text { Prevozno sredstuo } \\
\text { koje koristite pri } \\
\text { polasku u lov? }\end{array}$} & \multicolumn{2}{|c|}{$\begin{array}{l}\text { Ličči } \\
\text { automobil }\end{array}$} & \multicolumn{3}{|c|}{$\begin{array}{l}\text { Automobil } \\
\text { kolege }\end{array}$} & Biciklint & tocikl & & Pješak & \multicolumn{2}{|c|}{ Ostalo } \\
\hline \multicolumn{2}{|c|}{$\begin{array}{l}\text { Visina mjesečnih } \\
\text { primanja (neto) }\end{array}$} & \multicolumn{2}{|c|}{$\begin{array}{l}\text { Manje od } \\
100 \mathrm{kM}\end{array}$} & \multicolumn{2}{|c|}{$100-250 \mathrm{kM}$} & $251-4$ & $100 \mathrm{~km}$ & $401-5$ & $50 \mathrm{kM}$ & $551-700$ & $\mathrm{KM}$ & $e_{\mathrm{KM}}^{\mathrm{eod}} 700$ \\
\hline $\begin{array}{r}\text { Razlozi ba } \\
\text { Ilovon }\end{array}$ & $\begin{array}{l}\text { uljenja } \\
? ?\end{array}$ & Rekres & & Druženje & & Hobi & Komerc & & Rehat & abilitacija & Turizam & Ostalo \\
\hline $\begin{array}{c}\text { Koliko re } \\
\text { idete u }\end{array}$ & $\begin{array}{l}\text { douno } \\
\text { lov? }\end{array}$ & Višep & uta se & dmično & Više & puta goo & dišñje & & Vikendor & & Prvi & \\
\hline $\begin{array}{r}\text { Da li namje } \\
\text { se bavite } \\
\text { ubudu }\end{array}$ & $\begin{array}{l}\text { ravateda } \\
\text { ovom i } \\
\text { ce? }\end{array}$ & & & avezno & & & Povrer & neno & & & Neću & \\
\hline Ako $\mathrm{HE}$, z & ašto? & & & & & & & & & & & \\
\hline & & & & Koleg & & & Borav & k u pri & & & Psi & \\
\hline $\begin{array}{l}\text { Šta utiče } \\
\text { ugođaj }\end{array}$ & $\begin{array}{l}\text { na vaš prij } \\
\text { tokom loue }\end{array}$ & $\begin{array}{l}\text { jiatan } \\
\text { ja? }\end{array}$ & & adanje iz v & ratrenog & oružja & & ovliena & divljač & & Hrana is & \\
\hline & matrate li c & da su c & dstrij & jelne taks & se visok & ke? & & c & a & $\mathrm{Ne}$ & & le znam \\
\hline $\begin{array}{r}\text { Ako je odg } \\
\text { da }\end{array}$ & $\begin{array}{l}\text { ovor } \mathrm{ME}, \mathrm{m} \\
\text { la pojasnit }\end{array}$ & $\begin{array}{l}\text { nolimo } \\
\text { te. }\end{array}$ & & & & & & & & & & \\
\hline
\end{tabular}

Slika 2.: «Upitni obrazac»

Picture 2.: «Questionar»

Anketom je obuhvaćeno 12 lovačkih organizacija i udruženja u Srednjobosanskom kantonu/županiji:

1. LD «Radovina(Rog)»; Gornji Vakuf-Uskoplje. Prije rata 432 člana, sada 243;

2. LD «Bugojno»; Bugojno, Prije rata 750, sada 330. 
3. LD «Semešnica»; Donji Vakuf; Prije rata $\mathbf{4 7 5}$ članova, sada 171

4. LD «Srndać» Jajce-Vinac. Prije rata 630 članova, sada 349 članova. (Oba društva)

5. UL «Kuna»; Jajce

6. LD «Vlašić»; Travnik; prije rata 730, sada 376(Sokol-Nova Bila 150)

7. LD «Srndać»; Novi Travnik; Prije rata 335 sada 170 (Pavlovica)

8. LD «Kruščica», Vitez; prije rata $\mathbf{3 7 0}$ članova, sada $\mathbf{1 5 2}$

9. LD «Tetrijeb»; Kreševo; Prije rata članova, sada 165 članova

10. LD «Lještarka»; Kiseljak; Prije rata 223 člana, sada 255 (oba društva)

11. LD «Zec»; Busovača. Prije rata 315 članova, sada 283 člana(oba društva)

12. LD «Divokoza»; Fojnica; Prije rata 330 članova, sada 231 član.

\section{Rezultati}

Lovačke organizacije u istraživanom području do 1992 godine, imale su ukupno 4.800 članova. U poređenju sa ukupnim brojem stanovnika do 1992. godine, izlazi da je svaki sedamdeseti stanovnik u području bio član neke od lovačkih organizacija, odnosno, jedan lovac je dolazio na $0,66 \mathrm{~km}^{2}$ ukupne površine područja. Danas, ukupan broj članova u svim lovačkim organizacijama u području iznosi 2.875, što predstavlja smanjenje broja lovaca za 40,2\%, u odnosu na stanje iz 1992. Danas, u području, jedan lovac dolazi na $1,1 \mathrm{~km}^{2}$ ukupne površine, odnosno svaki 85 -ti stanovnik kantona se bavi lovom. Ukupan broj stanovnika u području danas, u odnosu na 1992. godinu, manji je za 26,88\% (245.504:335.752).

Anketom je obuhvaćeno ukupno 863 ispitanika, što predstavlja 30,02 \% od ukupnog broja članova svih lovačkih organizacija u Srednjobosanskom kantonu. Demografska struktura ispitanika je slijedeća:

$>$ Obrazovanje anketiranih članova lovačkih organizacija u istraživanom području je slijedeće: Oko $8 \%$ ispitanika ima visoko ili više obrazovanje, $61 \%$ ispitanika je sa srednjim obrazovanjem, dok čak 31 $\%$ ispitanika ima samo osnovno obrazovanje ili niže (Graf 1).

$>$ Profesija kojima se bave ispitanici, najveća zastupljenost je u kategorijama «Tehnička zanimanja» - 23,15\% i «Ostalo» - $34 \%$, dok su ostale kategorije «Ekonomist, Pravnik, Zdravstvo, Prosvjeta i Studenti» ukupno zastupljene sa svega $11,85 \%$. Značajno je da je čak $19 \%$ ispitanika penzioneri. (Graf 2).

$>$ Starosna struktura ispitanika je sa očiglednim deficitom najmlađih kategorija (mlađi od 20 i 20 - 35 godina), koje zajedno obuhvataju samo $9 \%$ ispitanika. Slijedeće dvije kategorije su podjednako zastupljene sa $40 \%$ (35 - 50 godina) i 37\% (51 - 65 godina), dok se u kategoriji «Stariji od 65 godina» nalazi $14 \%$ ispitanika. (Graf 3). 
> Kada su u pitanju mjesečna primanja, ispitanici su raspoređeni ovako: $7,01 \%$ ima primanja manja od $100 \mathrm{KM} ; 28,07 \%$ ima primanja $\mathrm{u}$ rasponu od $100-250 \mathrm{KM} ; 29,82 \%$ ima primanja od $251-400 \mathrm{KM}$; $16,14 \%$ ispitanika je sa primanjima od $401-550 \mathrm{KM}, 8,42 \%$ ima primanja od $550-700 \mathrm{KM}$; i 5,96 \% ispitanika ima primanja viša od 700 KM mjesečno(Graf 4).

- Najveći broj ispitanika su članovi lovačkih organizacija na području opštine u kojoj žive, odnosno njih 95,78 \%; 3,85 \% ispitanika žive na području drugih opština u $\mathrm{BiH}$, u odnosu na članstvo u lovačkoj organizaciji, dok su svega $0,3 \%$ ispitanika strani državljani (Graf 5).

> Najveći broj ispitanika ima od 20 - 30 godina lovačkog staža $(34,28$ $\%$, na drugom mjestu su ispitanici sa 10 - 20 godina staža $(32,85 \%)$; preko 30 godina staža ima 7,85\% ispitanika, 6,42\% ispitanika ima manje od 5 godina staža, dok je 3,6 \% ispitanika pripravnici u lovačkim organizacijama (Graf 6).

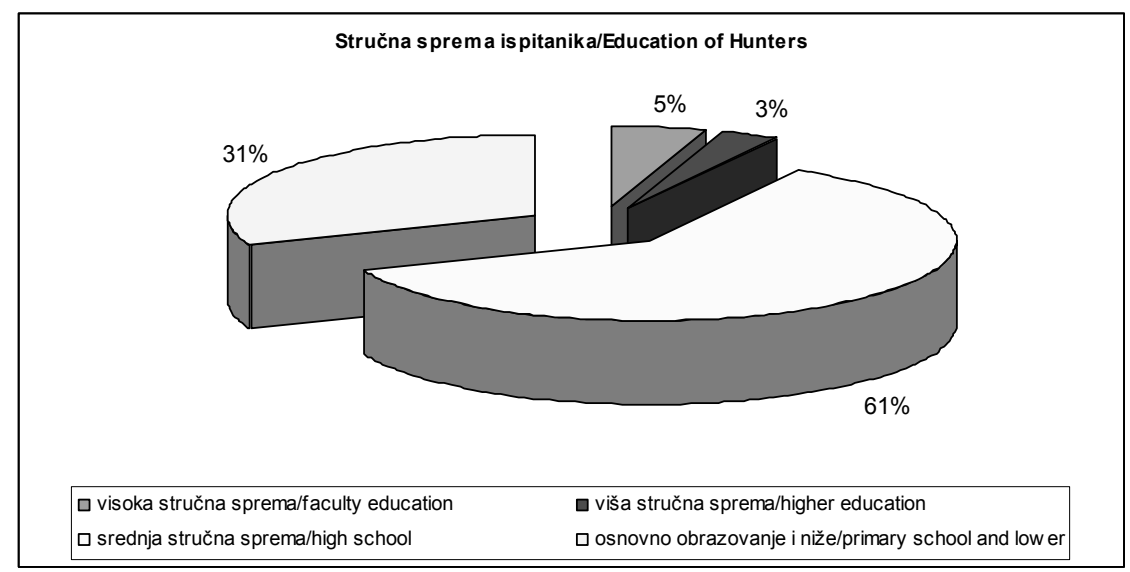

Grafikon 1.

Graph 1 


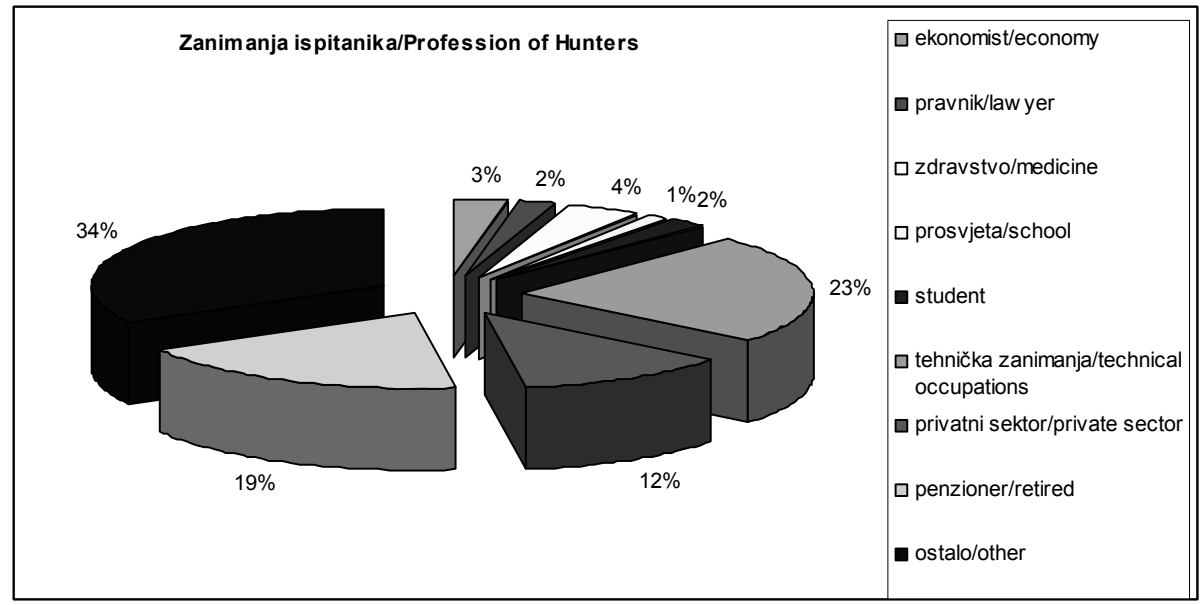

Grafikon 2.

Graph 2

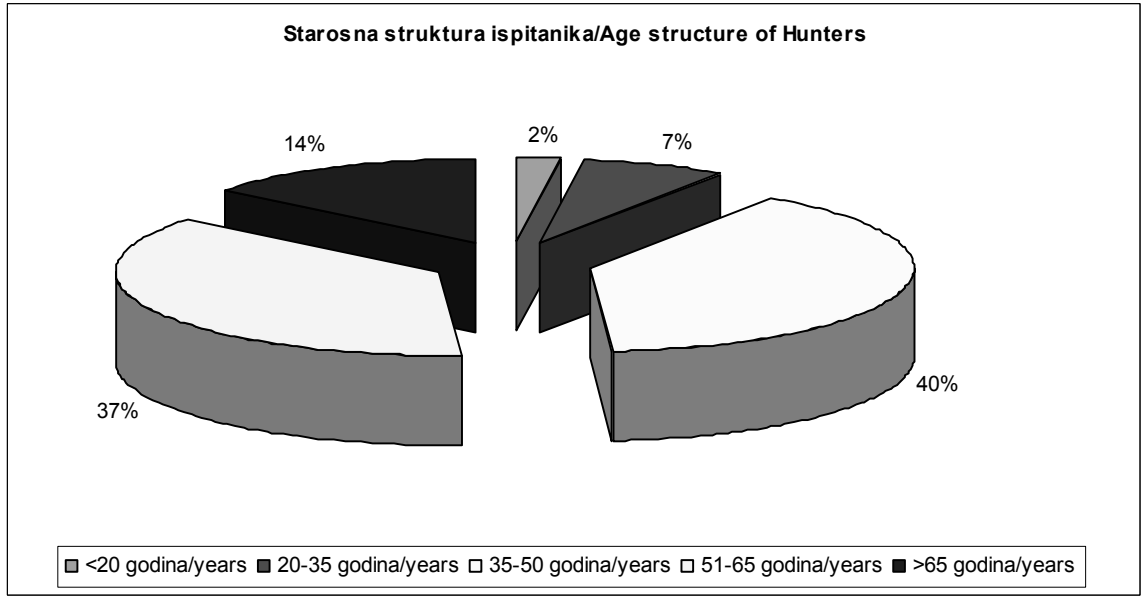

\section{Grafikon 3.}

\section{Graph 3}




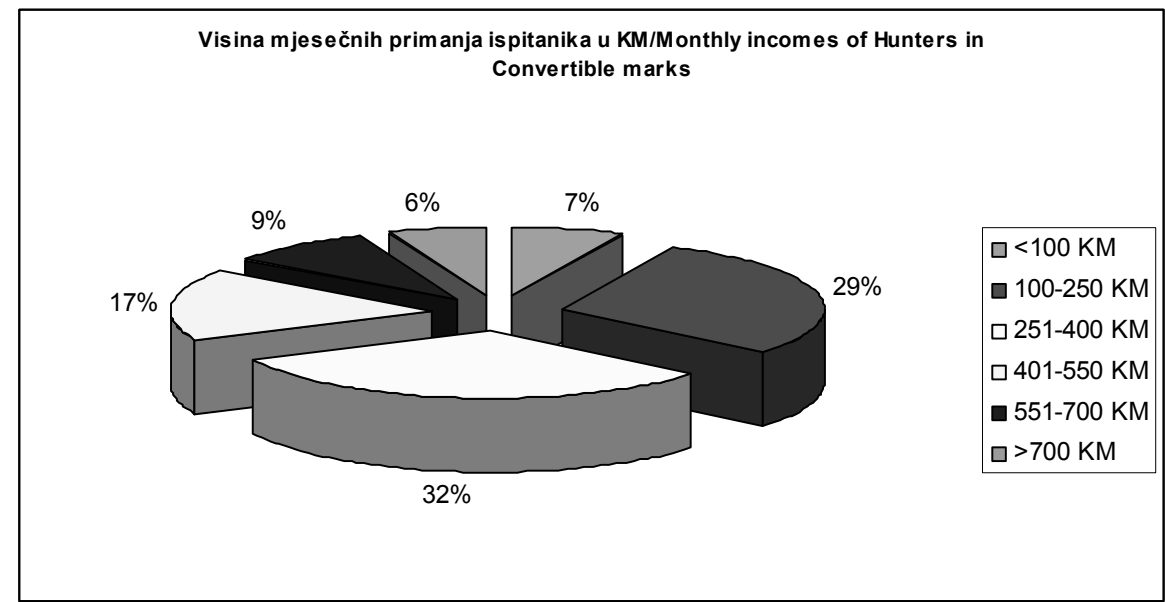

Grafikon 4.

Graph 4

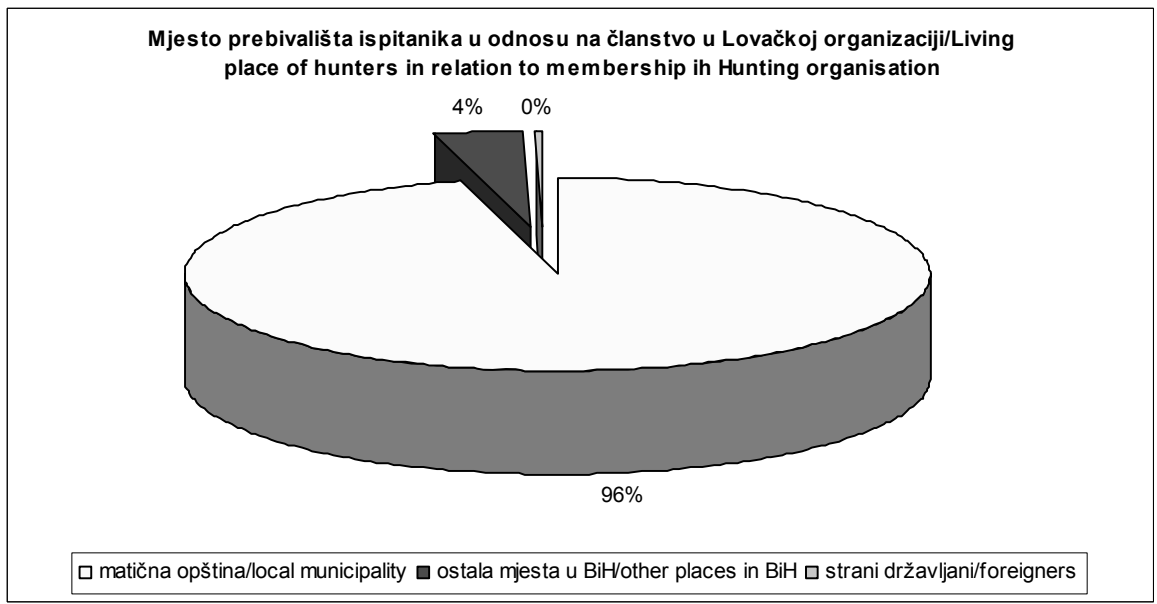

\section{Grafikon 5.}

\section{Graph 5}




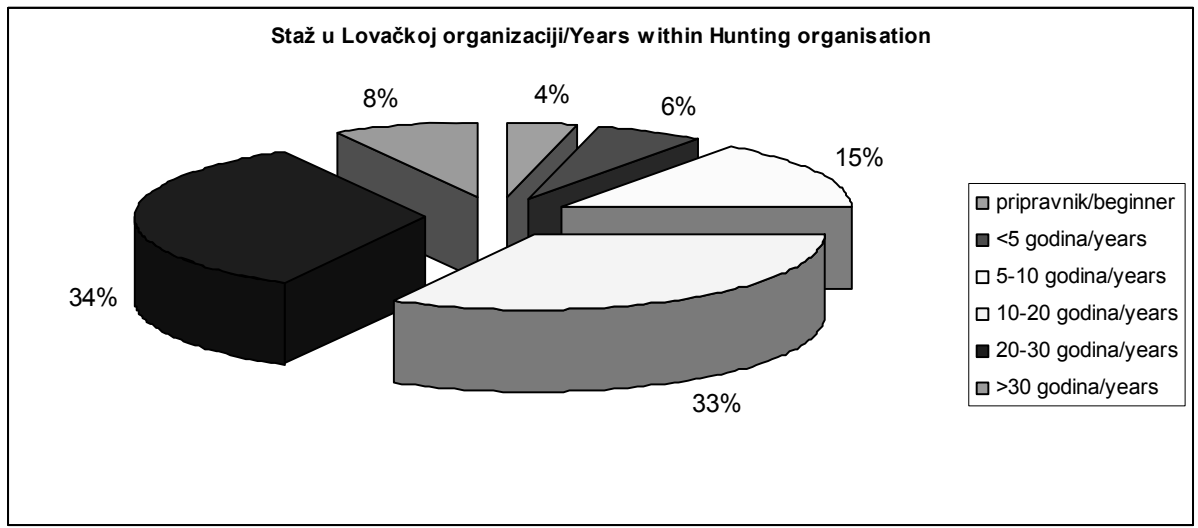

Grafikon 6.

Graph 6

\section{Diskusija i zaključci}

Prema podacima UNECE/FAO, drugu značajnu funkciju šuma u Evropi predstavlja lovstvo. U nekim zemljama istočne i zapadne Evrope, lovstvu se pridaje veliki kulturni značaj. Za mnoge vlasnike manjih privatnih šuma, lovstvo predstavlja najveći ili značajan dio prihoda, obzirom da se u Evropskoj Uniji najveći broj lovišta nalazi pod šumama i šumskim zemljištem (European Environment 1995.) danas, u zemljama Evropske Unije ima preko 7 miliona lovaca, a u oblasti lovstva zaposleno je oko 120000 ljudi.

Bosna i Hercegovina, kao zemlja sa još uvijek očuvanim prirodnim potencijalima za razvoj lovstva, može se reći, ne ostvaruje skoro nikakve prihode u ovoj oblasti. Razlozi su brojni: Nedostatak odgovarajućih zakonskih propisa, crno tržište, neuređenost lovišta, neobrazovanost lovaca i zastarjela shvatanja o lovu. Ovi pobrojani razlozi zajedno uzrokuju najvažniji: nedostatak divljači.

Za donošenje bilo kakvog programa razvoja lovstva u Bosni i Hercegovini i budućeg planiranja, potrebno je najprije utvrditi realno stanje na terenu. Ovo, svakako obuhvata inventarizaciju Bosanskohercegovačkih lovišta i divljači u njima, ali i inventarizaciiju samih lovaca, odnosno utvrđivanje njihove demografske strukture, mišljenja i zahtjeva kako bi se mogli donijeti adekvatni planovi edukacije i razvoja.

$\mathrm{U}$ istraživanom području, obzirom na strukturu obrazovanja ispitanika $(30,87$ \% ima samo osnovno obrazovanje ili niže, a $61 \%$ srednje obrazovanje), prioritet bi imali edukativni seminari, kursevi i slično, kako bi se izvršilo dodatno obrazovanje lovaca u oblasti lovstva.

Starosna struktura ispitanika je skoro alarmantna, jer deficit najmlađih kategorija ukazuje da kod mladih ljudi ne postoji interes za lovstvo, odnosno da mladi ljudi imaju određene averzije prema lovstvu, takođe, možemo zaključiti da će u bliskoj budućnosti lovci ostati bez mladog naraštaja, koji treba da odmijeni starije. 
Visina mjesečnih primanja svakako utiče na mogućnost bavljenja lovom, koji je veoma skup sport, a struktura ispitanika u ovoj kategoriji sigurno je imala uticaj na potvrdan odgovor na pitanje «Da li su odstrijelne takse visoke». Skoro $70 \%$ ispitanika ima mjesečna primanja do $400,00 \mathrm{KM}$, a mjesečna potrošačka korpa u Srednjobosanskom kantonu je 441,00 KM.

Razmišljanja ispitanika o značaju lovstva na matičnom području, te prijedloge mjera za unapređenje lovstva u području treba najozbiljnije shvatiti, jer se najveći broj odgovora slijeva u jedan: Zaštita divljači i eliminisanje krivolova. Imajući u vidu da su ova razmišljanja dali ljudi koji veliki dio vremena provode na terenu i imaju realan uvid u stanje divljači, odgovarajuće institucije u $\mathrm{BiH}$ bi što prije trebale preduzeti aktivnosti na donošenju i sprovođenju zakonskih propisa, koji bi regulisali ovo pitanje.

Ovaj rad predstavlja početak istraživanja o stvarnom stanju u lovstvu Bosne i Hercegovine, kako bi se lovstvo što prije unaprijedilo i dobilo značaj koji, realno i zaslužuje kao važan i nezaobilazan vid odmora, privredna grana i sredstvo za razvoj, prije svega ruralnih oblasti.

\section{SUMMARY}

According to UNECE/FAO, hunting is second most important function of forests in Europe. Today in EU we have over 7 millions of hunters and within this field 120.000 people are employed. Bosnia-Herzegovina, as a country with still preserved natural resources and potentials for intensive game management has almost no incomes in this field. Reasons are numerous: Lack of proper legislative in this field, black market, poor education of hunters, and all these reasons cause most important: lack of game animals.

For creating any serious program of hunting development in BosniaHerzegovina, we need to know real conditions at field. This presumes inventory of Bosnian hunting grounds and game populations, but also inventory of Bosnian hunters, their demographic structure, opinions and requests.

We conducted a research with questionnaire amongst 12 hunting organizations in Central Bosnia canton, and tested $30 \%$ of all hunters in area.

In research area, $30,87 \%$ of tested hunters have primary school or lower and $61 \%$ are with high school. According to this, education has a high priority.

Age structure of hunters in Central Bosnia canton is almost dramatically. Lack of younger categories points that young people lose interest for hunting, or have kind of aversion. Monthly incomes of hunters have a strong influence to possibility of being hunter which is very expensive, as shown in answer at question: «Are shooting taxes high? ». Almost $70 \%$ of hunter has monthly incomes not higher than 400, 00 $\mathrm{KM}$, and monthly life costs in Central Bosnia are 441, $00 \mathrm{KM}$.

Considering most of expressed opinions about significance of hunting in their home area and proposals for improving it, we can say that game protection and poaching are most important problems in nowadays situation. Those opinions come 
from people who spend most of the time at field and have real impression about game condition. So it's not only up to the hunters, but to Government institutions as well to support applying of Law and create new legislation.

This paper is beginning of inventory in Bosnia-Herzegovina game management and Hunting, for its improving and putting it into deserved place as important way of active recreation, sport and tool for rural development. 